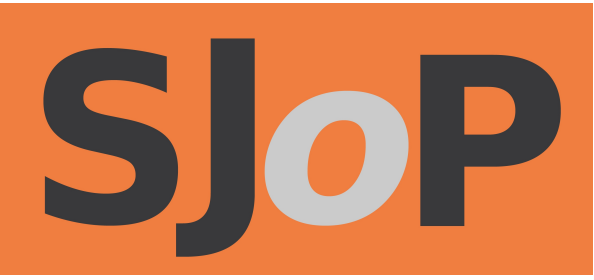

Symposium abstracts: Thresholds and permeability in performance

BEN FLETCHER-WATSON \& ADELINA ONG;

ADAM RUSH; ROSIE FIELDING; KELLI ZEZULKA;

KATHERINE GRAHAM; JONATHAN VENN;

SILVIA DUMITRIU; YARON SHYLDKROT;

ACATIA FINBOW; JENNIFER WILLETT; SARAH SLATOR;

BRIDIE MOORE, LAURA MURPHY \& MOE SHOJI;

LAURA MILBURN; EVE SMITH; KIRSTY SURGEY

The Scottish Journal of Performance

Volume 3, Issue 1; June 2016

ISSN: 2054-1953 (Print) / ISSN: 2054-1961 (Online)

Publication details: http://www.scottishjournalofperformance.org

To cite this article: Fletcher-Watson, B. and Ong, A. et al., 2016.

Symposium abstracts: Thresholds and permeability in performance.

Scottish Journal of Performance, 3(1): pp.97-114.

To link to this article: http://dx.doi.org/10.14439/sjop.2016.0301.07

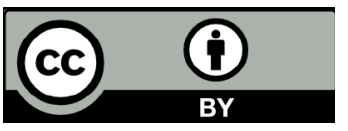

This work is licensed under a Creative Commons Attribution 4.0 International License. See http://creativecommons.org/licenses/by/4.0/ for details. 


\title{
Thresholds and permeability in performance
}

\author{
SYMPOSIUM ABSTRACTS:
}

BEN FLETCHER-WATSON \& ADELINA ONG; ADAM RUSH; ROSIE FIELDING; KELLI ZEZULKA; KATHERINE GRAHAM; JONATHAN VENN; SILVIA DUMITRIU; YARON SHYLDKROT; ACATIA FINBOW; JENNIFER WILLETT; SARAH SLATOR; BRIDIE MOORE, LAURA MURPHY \& MOE SHOJI; LAURA MILBURN; EVE SMITH; KIRSTY SURGEY

DOI: 10.14439/sjop.2016.0301.07

Publication date: 29 June 2016

Thresholds and permeability in performance

Saturday 6th February 2016

Humanities Research Institute, University of Sheffield

Funded by the Theatre and Performance Research Association (TaPRA)

Thresholds and permeability in performance was an event organised and hosted by PhD students Ben Fletcher-Watson (Royal Conservatoire of Scotland) and Adelina Ong (Royal Central School of Speech and Drama), with Cath Badham (University of Sheffield). Funded by the Theatre and Performance Research Association as a Postgraduate and Early Career Researcher Symposium, the day was intended to provide a collegiate, supportive atmosphere for postgraduate scholars to share and discuss their research. The event focused on the liminal spaces in between performance, with many areas of study represented, including live art, theatre, musicals, dance, livecasting and multimedia work. While theatre has often been presented in 
binary terms-actor / audience, reality / illusion, national / regional, canon / avant-garde-it can be productive to consider the blurred boundaries within and beyond performance.

The following abstracts represent a glimpse into contemporary research from around the UK. This was structured around five panels focusing on 'Between Nations and Nationhood', 'Uncovering the Intangible in Stage Lighting', 'Reality and Unreality in Contemporary Performance', 'Corporeal Documents' and 'Personal-PublicPerformed'. Presenters spoke about a wide range of subjects, from female impersonation in Shakespeare (Rosie Fielding) to performance throughout the life of an artwork (Acatia Finbow), and the 'private passions' of collector of theatre ephemera Roy Waters (Eve Smith).

Additionally, one session offered a pair of performance lectures, firstly using emotion mapping as entry into characterisation, emotional connectivity and authenticity on stage (Sarah Slator) and then occupying merging performance and reflection by saying 'no' (Bridie Moore, Laura Murphy and Moe Shoji). We would like to thank all of our presenters, chairs and delegates for attending the symposium.

BEN FLETCHER-WATSON \& ADELINA ONG

ADAM RUSH

No place like home: intertextual thresholds and the national mythmaking qualities of The Wizard of $\mathrm{Oz}$

The twenty-first century musical is undoubtedly an intertextual landscape formed from fragments of past popular culture. From the recycling of mainstream films to 
the nostalgic use of popular music, musical theatre is an art form littered with familiar and popular works that ultimately extend the cultural myths fashioned within certain texts beyond their original source. This paper focuses on the 2003 hit musical Wicked as a dominant site for the appropriation and continuation of the cultural myths perpetuated within the iconic American film The Wizard of $\mathrm{Oz}$ (1939), and the countless other intermedial texts which surround it. Though there are direct references to the 1939 film within the musical, this paper traces and analyses the broader thematic and conceptual similarities between such texts in the most part. In particular, it considers how the comforting conceptualisation of 'home' resonates throughout the $\mathrm{Oz}$ canon to argue that the dialectic relationship between any source and its adaptation is considerably more nuanced than the direct referencing of specific texts. In drawing upon Benedict Anderson's conception of an 'imagined community' and Will Wright's claim that myths are the 'social concepts and attitudes determined by the history and institutions of a society', this paper considers how the notion of 'finding' and 'returning' home is central to both the formation of $\mathrm{Oz}$, as a fantasy universe, and a national ideology which resonates across America through and between texts.

ADAM RUSH is a PhD candidate and Associate Lecturer at the University of Lincoln. His doctoral research explores the intertextual character of the twenty-first century musical and its role within popular culture. Adam recently produced and co-directed The Addams Family at the Edinburgh Festival Fringe and won the University of Lincoln's 'Three Minute Thesis (3MT)' competition in May 2015. 


\section{Performing the onnagata in Japanese / British} Shakespeare

There has been a growing trend in cross-cast, switched gender or single-sex productions of Shakespeare in recent years, a theme which has been particularly evident in Japan and Britain. In this paper I will investigate the methods of female impersonation used in Shakespearean performance in both countries, and consider how the attempt to 'reconnect' with the early-modern tradition of the boy player has led British artists to draw on theatrical genres from other cultures, most notably the onnagata in kabuki.

A large number of contemporary British artists have cited the onnagata as an inspiration for their cross-cast performances, both in terms of a historical precedent and as a stylistic inspiration, and have therefore built upon the onnagata's techniques to create a hybrid acting style that interrogates the performance of gender and fixed ideas of nation. The integration of performance methods from other theatrical forms reveals much about the way early-modern theatre is represented and understood in contemporary performance, and is particularly revealing of the sense of a lost connection with tradition and the past within British theatre. I argue that the artists engaging in this form of collaborative and experimental theatre have been attempting to investigate the similarities and differences between Japanese and British theatres, and have aimed to produce new and hybrid performer and audience identities. Studies on Japanese Shakespeare have tended to only look at the influence British artists have had on Japan, and so it is crucial to also look at this relationship from the other direction. 
UK Shakespeare performances. Her BA was in Japanese Studies at the University of Manchester, and her research is funded by the Midlands3Cities Doctoral Training Partnership and the AHRC.

\section{KELLI ZEZULKA}

\section{Communicating the intangible}

In his Tractatus Logico-Philisophicus, Wittgenstein maintains that 'the limits of my language mean the limits of my world'. Does the same hold true for the worlds we create on stage? For example, the principal artistic medium of a lighting designer is an intangible substance, visible only when it interacts with an object in space. Furthermore, the principal work of a lighting designer can only be done in situ, that is, in the actual performance space. In communicating about their work, lighting designers, therefore, are dependent upon the use and comprehension of two distinct languages-the 'artistic' language of ideas and intentions and the 'technical' language of processes and logistics. This ability to 'code-switch', often intersententially, is an important skill of the lighting designer, but can also be problematic. My presentation will explore the challenges lighting designers in particular face in translating artistic intention to technical processes, and how they (and, by extension, directors, electricians and lighting programmers) develop the vocabulary needed to articulate and respond to these, using theories of translation and translanguaging.

KELLI ZEZULKA is a theatre and opera lighting designer and a $\mathrm{PhD}$ candidate at University of Leeds. She is an executive member of the Association of Lighting Designers (ALD) and editor of its bi-monthly magazine, Focus. Her research interests include language and lighting, lighting design education and creative collaboration. 


\section{KATHERINE GRAHAM}

\section{Thresholds of possibility: dancing at the borders} of light

The artificially manipulated light of performance lies at an intersection of multiple temporal, perceptual, and dramaturgical processes. Light is at once the means of visual perception and a means of manipulating perception; it facilitates vision, yet can radically alter the appearance of a given object, environment, or person. The dynamic mediation of performance through light prompts, perhaps, a connection between the site and sight of 'crossing-over'. The notion of crossing-over implies a threshold, but also a transformation; a passage into, or a disclosure of, the unknown. In performances this threshold is made manifest, visually and spatially, through the ebb and flow of light.

This paper traces immaterial spatial boundaries of light as thresholds of possibility. Exploring liminal structures of light, I argue that Victor Turner's concept of liminality as a 'fertile nothingness' ('Are There Universals of Performance?': 12) is articulated visually through the appearance and disappearance of light-spaces in performance. In exploring the transformative potentiality of light I will focus on Piece No. 43, the latest work by the Russell Maliphant Company, which emerges from twenty years of collaboration between Maliphant and the lighting designer, Michael Hulls. Within this dance-work, space is continually reconfigured by light, as stark, sculptural boxes of light emerge, dissolve, and reappear elsewhere. This spatial instability, generated through the emergence of light-spaces, becomes a performance material in its own right, providing both prompt and possibility for the dancers' progression through space. 
Heideggerian concepts of being and disclosure. She has also worked extensively as a lighting designer; most recently No's Knife (Lincoln Centre, New York) and Blind Man's Song (Jacksons Lane).

\section{JONATHAN VENN}

\section{Unstable spaces, meanings of madness, and} auditory hallucination: uncertain voices in The Eradication of Schizophrenia in Western Lapland

Madness is often attributed its own private space; following Anna Harpin, our cultural idioms place madness as, 'an inherently geographical encounter' (2014: 187). Spaces of madness are often conceptualized through hallucination, whereby the 'hallucinatory' is laid bare and represented, lived experience transposed into material space. This troubling space of madness exoticises the experience even as it renders it knowable. We need to shift away from spaces of representation, attempting to ascribe particular meanings and definitions to hallucination. This paper will look at how alternative engagements of hallucination can breaches these thresholds of representation and redundant topologies of space.

The ambitious staging of Ridiculusmus' The Eradication of Schizophrenia in Western Lapland plays upon the notion of meaning making through hallucination. The stage (and the audience) is divided into two, by a long paper partition; two scenes play concurrently, one of a family drama, the other of a psychiatric session. Following the interval, the audience switch sides, and watch the alternative scene. I wish to suggest that, through the accumulation of staging, subject matter, and use of bodies, the play discovers a nonrepresentational attitude to madness. The space, in its latticing of perspectives and delusions, evades easy answers, and encourages the toleration of uncertainty. This resistance to simplistic representations leads to a nuanced approach to question of family and madness, that situates 
madness in a familial structure, without resorting to easy causations.

JONATHAN VENN previously completed a BA in Politics and Philosophy at Cardiff University and an MA in Writing for Stage and Broadcast Media at the Royal Central School of Speech and Drama. During his MA, he became interested in the representation of mental health, and how this informs modes of resistance and conceptions of agency. He is currently at Exeter University, in his second year of an AHRC-funded PhD in Drama, looking at how theatre can provide a site of resistance to hegemonic understandings of madness.

\section{SILVIA DUMITRIU}

\section{Theatricality and sovereignty in Forced Entertainment's work}

'The sovereign survivor in the postmodern culture is compelled to transgress' (Jenks, 2003, p.110). The freedom of the postdramatic performer is limited by his ability to subtract himself from the available discursive order, and constitute himself as a reflection of the system and ecologies generating notions of value; as such, postdramatic is contemporary with visionary discourses, which assert that 'man must reassume his position between dreams and events' (Artaud, 1971, p.71). A general economy dealing with the idea of scarce resources and the binary of consumption and production is reframed by Bataille's insistence that the system 'is a plenitude of energy, constantly recharged' (Jenks, 2003, p.102), where excess and waste constitute a dynamic of possibilities no longer limited by exchange value. A theatrical act that deals with the waste and surplus involves a reconsidering of life beyond utility, a questioning of the excess, luxury and creativity; the socio-historical process is reconsidered from the point of view of the sovereign subject as 'the possibility for a mingling of the most sacred and the unspeakable profane in their transgression of the restricted economy of utility' (Gallop, 
1981, p.11). Considering the role of this concept of sovereignty as the basis for a breakdown of hierarchies and a rethinking of the limit, I will attempt to illuminate the rethinking of theatricalised experience in relation with excess. The rethinking of the theatrical limit, the exposing of the stage apparatus producing appearances and rearticulating surfaces, the desire for presence and the failed attempt to bring back the plenitude evoked by the traditional stage, constitute in Forced Entertainment's work a meditation on the politicised notion of failure. As 'sovereignty and power have been amalgamated from the beginning' (Habermas, 1984, p.95), failure is a radical strategy for undoing the political desiderates at work in the given discourse of society which privileges performativity, unveils its play and exposes the circumstantial elements it subtends.

Silvia Dumitriu is a PhD student at the Royal Central School of Speech and Drama researching new theatrical structures in postdramatic theatre. She has extensive experience as a theatre director in Romania, and has written two plays, a Commedia dell'Arte for the twentieth century and a tragical farce. She has also translated more than 10 plays from French and English into Romanian.

\section{YARON SHYLDKROT}

\section{Looking on darkness: theatre in the dark on the threshold of documentation}

Documentation is a key element for both practice and research. Pictures, DVDs, audio recordings, sketches, personal and academic writing are only some of the tools for capturing and presenting artistic work. Although Peggy Phelan's famous assertion that performance 'cannot be saved, recorded, documented' (1993, p.46) provoked a rich discussion about the ontology and ephemerality of performance, documentation still proves itself to be a necessity in the current theatre climate. In response, many 
artists and scholars still default to video recording and images. Yet, what happens when there is nothing to see?

In this presentation I examine the limitations and boundaries of documenting theatre in the dark. In a world that relies heavily on sight and where 'seeing is believing', theatre in the dark brings forward experiences of notseeing / seeing-nothing that cannot be effectively visually captured. When plunging audiences into darkness a strong sense of uncertainty and disorientation arises that disrupts the perception of reality and entails different modes of engagement with the performance (and the world). It therefore requires other modes of documentation.

Informed by own work as a practitioner-researcher creating work in the dark, and examining different experiences created by other practitioners and companies (Sound\&Fury, David Rosenberg, Lundahl \& Seitl), I wish to explore the translation of the uncertain experience in and through the document. To do so, I will outline the disruption of perception accruing when being in total darkness, discuss the paradoxical need to share the un-photographed and explore alternative attempts for documenting theatre in the dark. Eventually I wish to utilise this apparent practical and methodological problem to rethink the different functions a document may fulfil or offer to other practices such as dance, immersive and participatory theatre as well as Practice-based PhDs.

YARON SHYLDKROT is a practitioner-researcher in the early stages of a Practice-as-Research $\mathrm{PhD}$ at the University of Surrey, exploring dramaturgies of uncertainty in pitch-black theatre. He holds an MA in Advanced Theatre Practice from the Royal Central School of Speech and Drama. As a performance maker, he co-founded Fye and Foul, a theatre company exploring unique sonic experiences. 


\section{ACATIA FINBOW}

\section{The Permeability of the performance document:} Rebecca Horn's Body Sculptures at Tate Modern

The contemporary art museum exhibition is a complex site. Superficially a neutral space of contemplation, it is imbued with social, political, and historical contexts and is a place of interpretation, dissemination and encounter, where the permeability of objective truth can be exposed and manipulated. When live art, in its various forms, enters the space of exhibition, it crosses a threshold into the institution's influence, to be shaped by the acts of curation and display. It comes to occupy a space between the immaterial and the permanent, between the event and the object, and puts the museum visitor in a unique viewing position, which intimately merges experiences of the performance in the past, present, and future.

This paper will focus on the display of Rebecca Horn's performance-focused 'Body Sculptures' at Tate Modern, in the Making Traces collection display. Addressing the display of documents rather than live performance in the museum, this paper will explore not just the residue of the performance within the documents, but how the act of performance permeates the materials on display and allows the museum visitor to experience performance as part of the wider life of the artwork. It will argue that performance does not just happen in the transient moment of the live event, leaving the documents as mere traces or echoes, but exists in different ways throughout the extended life of the artwork, from initial creative inception to eventual museum display.

ACATIA FINBOW is a collaborative doctoral student at Tate and University of Exeter, where she is part of the AHRC-funded Performance at Tate research project. Her thesis focuses on the value of the performance document in the contemporary art museum, considering the variety of documents held in Tate's archive and collection. 
Multimedia, livecasting and interactivity: where digital meets live

This paper examines the impact of interactive, digital and live documentation taking place in performance settings. As the relationship between the recorded and live becomes more complex through the proliferation and ubiquity, the question of what can and cannot practically be documented increases. For humans there can be lapses of memory when recalling a performance event and often the fragmented and multi-perspective nature of the performance is lost in the historical documentation, potentially resulting in being in the space becoming the primary method of documenting. The audience members bodies can be understood as part of the archive and part of the process resulting in untrained body(ies) in the space which hold the capacity for a new form of documentation.

Within my practice I am working with an emerging ensemble to generate fragments of task-based performance. This closed laboratory environment is periodically opened through the use of participatory work demonstrations, livecasting and online platforms. Audience members are invited to interact with the laboratory, as well as, the digital and physical documentation, (re)activating and bringing the documentation back in to the now of the (re)enacted laboratory.

As I explore methods of bringing untrained body(ies) into the laboratory, both through a virtual and physical presence, I persist in exploring how training, research and documentation can consider the body(ies) as archive and the body(ies) of the archive. Therefore, this paper will consider the significance of bringing the documentation into the now of the laboratory. 
JENNIFER WILLETT is a final year Practice-as-Research PhD student and Graduate teacher in the School of Arts and Media at the University of Salford. Her specialism is contemporary theatre with research interests that include the formation of emerging performance ensembles. More specifically, her work examines the relationship between the individual and the collective in emerging performance ensembles.

\section{SARAH SLATOR}

\section{Emotion, the Individual, the Actor and the}

Character: is incitement of the performer's subjective physiological experience of emotion a vehicle for characterisation?

Enquiry into the division of consciousness when on stage has prompted personal consideration of the performer as a trinity formed of Self as Individual, Self as Actor and Self as Character. Whilst own concern has previously focused on development of Self as Actor and Self as Character, discourse in cognitive psychology, in particular Cognitive Dissonance, spurred interest in utilisation of Self as Individual as a short-cut into embodiment of role.

Through staging an adaptation of Shakespeare's Romeo and Juliet, self-awareness and use of subjective, topographical analysis of emotion-generated sensations in the body were explored as entry into characterisation and emotional connectivity and authenticity on stage. Use of the technique as a method of expediting process was also considered.

Inspired in response to existing psychological research by Nummenmaa et al. (2014) and developing consideration of the phenomenological performer, individuals incited emotion in response to external object stimuli and developed personal coloured emotion maps with selfallocated adjectives to describe the felt sensations. The methodology of this approach in rehearsal is discussed and contextualised within the context of past and current 
psychological and theatrical practice.

Subjective evaluation by myself as practitioner and the performers with whom I worked, identifies further potential for use of emotion mapping and suggests its effectiveness as a 'safe' method for repeatable generation of emotional connectivity through self-stimulation of the physiological responses identified.

SARAH SLATOR is an emerging theatre director and researcher interested in how treatment of the holistic performer might offer greater authenticity in acting. Having recently completing Masters study at the Guildford School of Acting, she is now working professionally within the theatre industry.

\section{BRIDIE MOORE, LAURA MURPHY \& MOE SHOJI}

\section{Between thinking and making, yes and no}

In 2008 Terry O'Connor started work on Say the word, an exploration into forms and agreements at the edge of collaboration. The project developed into an AHRC Fellowship at Roehampton University (2009-15) and continues as a body of practice outside her work with Forced Entertainment. Words sent by fifteen different artists became starting points for essays into extreme or marginal forms for collaborative exchange. These 'starter words' began to resemble incomplete orders, something like instructions, something like invitations, nothing like these as well. The practice has become an unfinished and unfinishable game. The project attempts to think about the permeable borders between conversation and creative work, about areas of command and performance within theatre collaboration. It follows Brian Eno's suggestion of 'seed' art, unfinished chains of thought, deliberately invoking contestable zones of authorship, ownership and participation through playful iterative outcomes. 
Recent work on the word 'no', (sent by artist Sophie Calle), begun at the University of Sheffield with Terry O'Connor and PhD students Moe Shoji, Laura Murphy and Bridie Moore, will be cited and performed in a fifteen minute performative lecture, occupying a territory between performance and reflection.

Bridie Moore: Following Kathleen Woodward (1991), to reject our mirror image as we age produces a disconnection between the visible manifestation and the subjective experience of identity.

Laura Murphy: addressing the colonization of the female body in western society, through exploration and reflection of experiences living, as a woman, in the world at present.

Moe Shoji: Exploring culturally specific implications in naysaying, between projected and self-identified identity.

BRIDIE MOORE is a PhD candidate at the University of Sheffield researching performances of age and ageing through practice. She focuses on questions of performativity, exploring notions of age as culturally constructed. In 2012 she formed Passages Theatre, a group of performers over the age of 50, who have produced two shows: The Mirror Stage and A Blueprint for Ageing.

LAURA MURPHY is a performance artist, aerialist, theatre maker and doctoral researcher at the University of Sheffield. Her research investigates aerial performance as socially critical, and the relationship between circus and live art. Her recent work My Brain is a Radio investigated anxiety disorder, and utilized aerial rope and ground based improvisation.

MOE SHOJI is a PhD candidate in Theatre and Performance Studies at the University of Sheffield. Her research topic is 'Paratext in Contemporary Theatre Practice', in which she argues that traditionally 
marginal aspects of theatrical performance (i.e. paratexts) are becoming increasingly important in meaning-making processes in contemporary theatre performance.

\section{LAURA MILBURN}

\section{Noël Coward: on and off stage}

'I wonder why it is that my plays are such traps for directors, as my lyrics are for singers. Nobody seems capable of leaving well enough alone and allowing the words to take care of themselves. Neither my lyrics nor my dialogue need decoration; all they do require are clarity, diction and intention and the minimum of gesture and business.' Following his advice, by the 1930s, Coward was an iconsophisticated and adored by high society; a man at the peak of his career. Coward's comic play Present Laughter is considered to be semi-autobiographical, with Coward playing Garry Essendine-a successful, self-obsessed actor. He claimed he wrote the play with the 'sensible object of providing me with a bravura part'; it being 'a potent mix of self-exposure and self-celebration.' Looking at Coward's multi-faceted career, one has the opportunity to appreciate the diversity of it.

LAURA MILBURN is an MMus candidate at the University of Sheffield. She is researching several of Noël Coward's musicals under the supervision of Dr Dominic McHugh.

\section{EVE SMITH}

Roy Waters and the archival tourist: bringing the private passions of the theatre collector to the threshold of public communication

The private collection of theatrical ephemera is replete with personal stories, memories, and traces of both the past theatrical event and the life of the individual who gathered and preserved the collected materials. When the private collection crosses over into the public archive, these private 
stories reach the threshold of public communication, some for the very first time. As the first researcher to work on the private theatre collection of Roy Waters in its new home in the college archives of Royal Holloway, University of London, this paper introduces the private passions of a hitherto uninterrogated collector of theatrical ephemera to a public audience. In the making public of these personal histories, the archival researcher is, to coin Laura Engel's evocative term, an 'archival tourist', navigating their way through the archive; an archive in which antithetical notions of public and private, past and present, and the living and the dead degenerate and disintegrate, slip and seep. In the context of the private theatre collection and the public theatre archive the border or boundary that separates and defines the two spaces becomes diaphanous, permeable and unstable. Arlette Farge suggests that: 'We cannot bring back to life those whom we find cast ashore in the archives. But this is not a reason to make them suffer a second death.' In excavating the life of the theatre collector, the archival tourist is a living body through which private passions and personal and theatrical histories can be revived, publicised, and performed, told and re-told.

EVE SMITH holds a CDA with the Victoria and Albert Museum and Royal Holloway, University of London. Her research investigates the private passions of the collector of theatrical ephemera and examines approaches to the private theatre collection in the context of the public archive.

\section{KIRSTY SURGEY}

\section{Washing your dirty linen in public: The ethics of placing personal history on a public stage}

Using personal history in a public performance alters the story. The story that was once private is now public. It becomes something different. Family history can give an individual a sense of belonging and a way to engage with a wider historical narrative. Yet this connection is necessarily 
shared. It is shared with other family members, with the subject of the story, as well as with other players in the narrative. This brings into question the ownership of the story and if this is uncertain then the ethical responsibility of the performance maker is complicated. Moreover, if the stories and histories that an individual wishes to share are unpleasant or reveal skeletons that other family members wish to remain hidden, does the performance maker have a greater responsibility to protect the reputation of the individual or to telling the truth as it is known? In Carran Waterfield's solo piece The House, her exploration of performance for the welfare state challenges the audience's understanding of what is private, personal or public. Waterfield uses theatre as a device to expose her history by shifting it into the public arena. In this paper, I will consider the ethical questions that arise when moving stories across this boundary from private to public.

KIRSTY SURGEY is a WRoCAH-funded practice-based PhD student at the University of Sheffield. Her research investigates how performance can be used to explore the relationship between public and private history. She has previously presented papers at conferences at Royal Holloway University of London and the University of Kent.

\section{Acknowledgements}

The Theatre and Performance Research Association was founded in 2005. http://www.tapra.org 